\title{
Modeling Extinction Risk for Seabirds in Brazil
}

\author{
Nathália Machado ${ }^{1 *}$, Daniel Brito² \& Rafael Dias Loyola²
}

\author{
${ }^{1}$ Programa de Pós-graduação em Ecologia e Evolução, Instituto de Ciências Biológicas, \\ Universidade Federal de Goiás - UFG, Goiânia, GO, Brasil \\ ${ }^{2}$ Departamento de Ecologia, Universidade Federal de Goiás - UFG, Goiânia, GO, Brasil
}

\begin{abstract}
Species extinction risk is associated with intrinsic features such as body mass, geographic range size and diet, and also with external threats, mainly anthropogenic pressure. Current biological knowledge on seascapes still falls behind knowledge from terrestrial ecosystems, and understanding the pathways to extinction for declining groups, such as seabirds, is of paramount importance. Here we provide the first estimates of seabird extinction risk derived from regressive models associating species intrinsic features and external threats, and evaluation of effectiveness of marine protected areas (MPA). We aimed to: (i) understand how intrinsic and external variables interact to set pathways to seabird extinction; (ii) define which variables are most important; (iii) evaluate the geographic structure of extinction risk; and (iv) evaluate the effectiveness of Brazilian MPAs in representing species at high and low risk. We used classification tree to model extinction risk and random forest to evaluate the importance of each variable. Our models were accurate to predict relative extinction risk of threatened species. Breeding range size and threat from fishing vessel were the most important correlates of extinction risk. Brazilian MPAs are not effective to protect seabirds and are short to cover a minimum of $10 \%$ of species ranges. We show that correlates of extinction risk act in a synergistic way and suggest that conservation of seabirds in Brazil should be considered high priority given their low current level of protection.
\end{abstract}

Key words: Classification Tree, Marine Birds, Protected Areas, Seascapes, Species Loss.

\section{Introduction}

Species extinction risk has been largely associated with biological traits such as body mass (Gaston \& Blackburn 1995), geographic range size and diet (Purvis et al. 2000), clutch size and fecundity (Bennett \& Owens 1997). External threats have also a crucial function to define extinction risk and several studies have reported threats that lead species to extinction such as habitat conversion, hunting, climate change, and alien species invasion (Sodhi \& Ehrlich 2010). Species responses to external threats can vary given their evolutionary history, behavior, and intrinsic biological features. Thus, multiple intrinsic and extrinsic features define extinction risk (Davidson et al. 2009) and, because threats change over the time, species extinction is better understood if one analyzes both external threats and intrinsic features together (Cardillo et al. 2006).

Most studies on extinction risk have been conducted for terrestrial species. In marine environments, fishes are largely more studied than other groups of organisms, given the economic importance of fishery activities (Pinsky et al. 2011). However, seabirds also play a critical role in marine

\footnotetext{
*Send correspondence to: Nathália Machado

Departamento de Ecologia, Universidade Federal de Goiás - UFG, CP 131, CEP 74001-970, Goiânia, GO, Brasil

E-mail: piayanms@gmail.com
}

community structure and ecosystem functioning, acting as top predators (Sergio et al. 2008). Yet, concerns about the ecological integrity of seascapes are increasing fast due to ongoing habitat degradation caused by human activities (Halpern et al. 2008). Less than $1 \%$ of the world's seas are currently under protection, in contrast to the $11 \%$ of global land coverage provided by protected areas (Toropova et al. 2010). Thus, the target to protect at least $10 \%$ of coastal and marine areas until 2020 is still far from being achieved. Adding to this problem, only the presence of protected areas does not indicate that they are effective in achieving biodiversity conservation.

Over the last 20 years seabirds received smaller conservation attention and effort compared to non-seabirds, and thus seabird populations are declining fast (Croxall et al. 2012). It is generally assumed that the vulnerability is similar both to terrestrial and marine species, but unexpected patterns can emerge when analyses include only marine species (Pinsky et al. 2011). Hence, understanding how biological features and external threats interact to define seabird extinction risk allows for more robust quantitative predictions of extinctions and helps us to evaluate the geographic structure of extinction risk - both crucial steps to help us set more effective conservation actions. 
Here we provide the first estimates of seabird extinction risk derived from models that associate intrinsic biological features and external threats, evaluating also if species under high risk are well represented in marine protected areas (MPAs). We aimed to: (i) understand how intrinsic biological features of seabirds and external threats interact to set different pathways to species extinction, (ii) define which features are key drivers of extinction risk, (iii) evaluate how extinction risk is spatially distributed, and (iv) evaluate the effectiveness of MPAs to protect seabird biodiversity, using the species of Brazil as our case study.

\section{Material and Methods}

\section{Data}

We built a database of seabird species occurring in marine habitats in Brazil ( $\mathrm{n}=54$ species, excluding vagrant species). We chose biological features according to their role in defining extinction risk as reported in the literature, as well as on the basis of data availability. We used the following intrinsic features: (1) total geographic range size (i.e. global distribution) and (2) total breeding range size [both in $\mathrm{km}^{2}$ and based in extent of occurrence maps provided by BirdLife International and NatureServe (Ridgely et al. 2011)], (3) mean body mass of adults (in grams), (4) diet (piscivore, carnivore, insectivore and omnivore), (5) diet breadth (number of type of items in their diet), (6) mean clutch size, (7) habit (nocturnal, diurnal or both),(8) type of habitat (the habitat primarily used by species: sand beaches/ coastal water or pelagic water), (9) number of habitats the species occur [7-9 according to Stotz et al. (1996)], (10) migratory behavior (non-migrants or migrants), (11) foraging strata (terrestrial, water and aerial), (12) foraging site(water, ground, vegetation, air, mixed, (13) foraging site breadth. We compiled all these data from several sources (see Appendix S1 in Additional Supporting Information available at www.abeco.org.br).

We also used external threats for each species from the Red List of Threatened Species published by the International Union for Conservation of Nature (IUCN 2011). These threats were: (14) threat by fishing vessel, (15) habitat disturbance, (16) predation by introduced species, (17) hunting or harvesting, (18) diseases, (19) prey overexploitation, and (20) climate change. We associated external threats to each species according to the information available in the IUCN Red List (IUCN 2011). These threats were treated as a binary variable in our analysis. For example, if a given species is threatened by habitat disturbance according to IUCN (2011), it was assigned a " 1 " to this threat in our data matrix. Otherwise, if the species is not threatened by habitat disturbance, then it received a value of "0" (zero).

We also used species threat status according to IUCN (2011). The Red List assigns species into different threat categories using distinct criteria: (A) species threatened because of recent population declines;(B) species threatened because of small geographic distribution, and (C) and (D) species threatened because of small population sizes $(<2500$ individuals, and $<250$ individuals, respectively) and Criteria $\mathrm{E}$ - species threatened based on quantitative analysis. We excluded all seabird species listed as threatened under criterion B by IUCN Red List (species threatened because of small geographic size) to avoid potential circularity in the extinction risk model, given that range size was set as a predictor in our analyses. Further, we did not include species listed under criterion $\mathrm{E}$ because there is no species listed under this criterion in Brazil. We considered species classified by IUCN criteria as 'Least Concern' (LC) and 'Near Threatened' (NT) as 'non-threatened', and species classified as 'Vulnerable' (VU), 'Endangered' (EN), and 'Critically Endangered' (CR) as 'threatened' species. We downloaded data on the network of integral marine protected areas in Brazil (henceforth MPAs) from protectedplanet.net.

\section{Analyses}

We modeled the relative extinction risk using decision tree, a logical model represented by a binary tree that shows how the response variable (in our case, threat status: threatened or non-threatened) can be predicted by the explanatory variables (here, intrinsic biological features and external threats) (Breiman et al. 1984). When decision tree has a categorical response (such as threatened or non-threatened) it is called classification tree. This technique was designed to deal with complex interactions such as those related with extinction risk, which can differ among taxa in a non-linear ways (De'ath \& Fabricius 2000). Thus, two key principles could be incorporate to our model using the classification tree approach: more than one factor can threat species, and the factors can be important only in particular situations with synergic action to others variables (Davidson et al. 2009).

Decision tree models are particular useful in our case because, differently from linear regression models, they do not assume/ require (1) any specific statistical distribution of predictor variables, neither (2) data independence, avoiding potential concerns about pseudo-replication (De'ath \& Fabricius 2000). During the analysis, the model splits the initial dataset into subsets as homogeneous as possible in terms of the response variable, using one predictor variable at each node. We measured homogeneity within response variable subsets with the Gini Index (Breiman et al. 1984). The initial result of the classification tree is a usually large tree that could be an over-fitted tree. Thus, we pruned the tree to its optimum size using the results of 10 cross-validations, making a trade-off between prediction accuracy and complexity of the model. To estimate the relative extinction risk of species we divided the number of species currently threatened in each node [according to IUCN Red List (IUCN 2011)] by the total of species, in each node.

To evaluate the contribution of each variable in predicting extinction risk we built 499 random classification trees, using random forest. Random forest is a method that builds 
many independent classification tree models excluding a subgroup of predictor variable at each time from the model and combining the results of all trees (Liaw \& Wiener 2002). Therefore, comparing the accuracy of the models built by random forest, we could access the importance of each biological feature used to predict the extinction risk.

To evaluate the accuracy of the overall models we used Cohen's Kappa statistics (irr package in the R software; Gamer et al. 2010) that measures the concordance between the species categorization (threatened or non-threatened) generated by the model and the current status based on the IUCN Red list (IUCN 2011). In addition, we calculated percentage of species correctly classified (PCC), non-threatened species correctly classified (specificity) and the percentage of threatened species correctly classified (sensitivity). We ran all analyses in $\mathrm{R}$ software using rpart package to build classification trees and the randomForest package to run the random forests (Liaw \& Wiener 2002).

We also mapped species predicted as threatened and non-threatened by our model to show how extinction risk is geographically structured in Brazil. The geographic extent of our analyses was the Brazilian Exclusive Economic Zone (EEZ) and Continental Shelf, which was divided into $0.25^{\circ} \times 0.25^{\circ}$ of latitude/longitude grid cells. To evaluate the effectiveness of MPAs, we quantified how much of the geographic range of seabirds in Brazilian EEZ and Continental Shelf is covered by MPAs, and how many species are included in MPAs. Here, instead of total geographic range previously used to model extinction risk, we used only range placed in Brazilian jurisdiction (in Brazilian EEZ and Continental Shelf). We overlaid species' distribution to the network of MPAs currently established in Brazil (no-take zones or IUCN strict protected areas categories I-IV). Then, we calculated the proportion of their geographic range located inside protected areas (i.e. their current level of protection). All species with at least one grid cell of their range overlapped by MPAs were considered as represented in MPAs.

\section{Results}

We found different pathways to seabird extinction, as well as threshold values for features contributing more or less to extinction risk (Figure 1). In Brazil, seabirds had ca. $16 \%$ of extinction risk (Figure 1, node A). Extinction risk can be modulated to higher or lower values depending on which variables are included in the model. Species threatened from fishing vessels had very high extinction risk (61\%, Figure 1, node B). Species with larger total breeding range size (higher than 505,000 $\mathrm{km}^{2}$ ) had lower extinction risk ( $0 \%$, Figure 1, node D). However, species with smaller breeding range size had higher extinction risk values (72\%, Figure 1, node E) and when they had smaller clutch size their extinction risk increase (87\%, Figure 1, node F). Additionally, the most important variables driving extinction risk in seabirds were breeding range size and fishing vessel, respectively (Figure 2).

Optimal classification tree, pruned based on the results of 10 cross validations (Figure S1 in Additional Supporting Information), had three splits and had the same size of the expanded tree (Figure 1). Both tree classification models, as well as the random forest model, were accurate to predict relative extinction risk and threatened species (Table 1). Additionally, only two species currently listed as threatened by the IUCN Red List were predicted to be non-threatened by our model (the Trindade Pretel, Pterodroma arminjoniana and Olrog's Gull, Larus atlanticus).

Species richness varies along the Brazilian coast (Figure 3A). Species under low extinction risk are located mainly in the coastal region (Figure 3B), where as those with high extinction risk are concentrated in southern Brazil (Figure 3C). Also, the proportion of species' range inside MPAs was lower for species under high extinction risk ( $1 \% \pm 0.5$ of their range size) compared to those under low extinction risk $(28 \% \pm 23$ of their range size).

\section{Discussion}

Seabird conservation undergoes a fragile moment: we must identify or better understand how different predictors interact to guiding them to extinction and also, how extinction risk is spatially structured (Croxall et al. 2012). We showed that Brazilian MPAs are highly deficient to protect seabirds [as other biodiversity features, see Magris et al. (2013)], either those species with high extinction risk, and those with low extinction risk, even under a broad criteria used by us to define species as represented (at least, one cell grid of overlapping). This is no surprise as Brazilian MPAs overlap with only very few Important Bird Areas (IBAs)

Table 1. Accuracy measures for predictions of seabirds' extinction risk in Brazil $(\mathrm{n}=54)$.

\begin{tabular}{lccc}
\hline \multicolumn{1}{c}{$\begin{array}{c}\text { Accuracy } \\
\text { metric }\end{array}$} & $\begin{array}{c}\text { Classification model } \\
\text { Classification tree: } \\
\text { expanded }(\mathbf{n}=\mathbf{3})\end{array}$ & $\begin{array}{c}\text { Classification tree: } \\
\text { optimal }(\mathbf{n}=\mathbf{3})\end{array}$ & $\begin{array}{c}\text { Random } \\
\text { forest }\end{array}$ \\
\hline PCC & $94.4 \%$ & $94.4 \%$ & $90.7 \%$ \\
Specificity & $97.8 \%$ & $97.8 \%$ & $97.8 \%$ \\
Sensitivity & $77.8 \%$ & $77.8 \%$ & $55.6 \%$ \\
Error rate (null error=1.7\%) & $5.6 \%$ & $5.6 \%$ & $9.3 \%$ \\
Kappa $(p$-value) & $0.79(<0.0001)$ & $0.79(<0.0001)$ & $0.62(<0.0001)$ \\
\hline
\end{tabular}




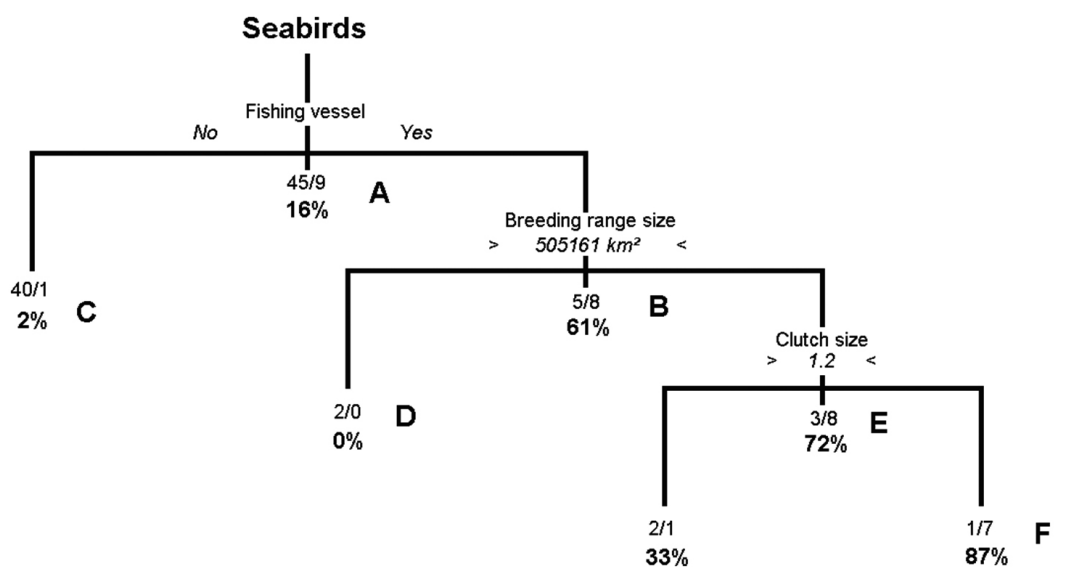

Figure 1. Classification tree showing seabird extinction risk in Brazil according to their intrinsic biological features and external threats, and the number of species currently non-threatened and threatened at each node (non-threatened/threatened). Labeled nodes are referenced in main text.

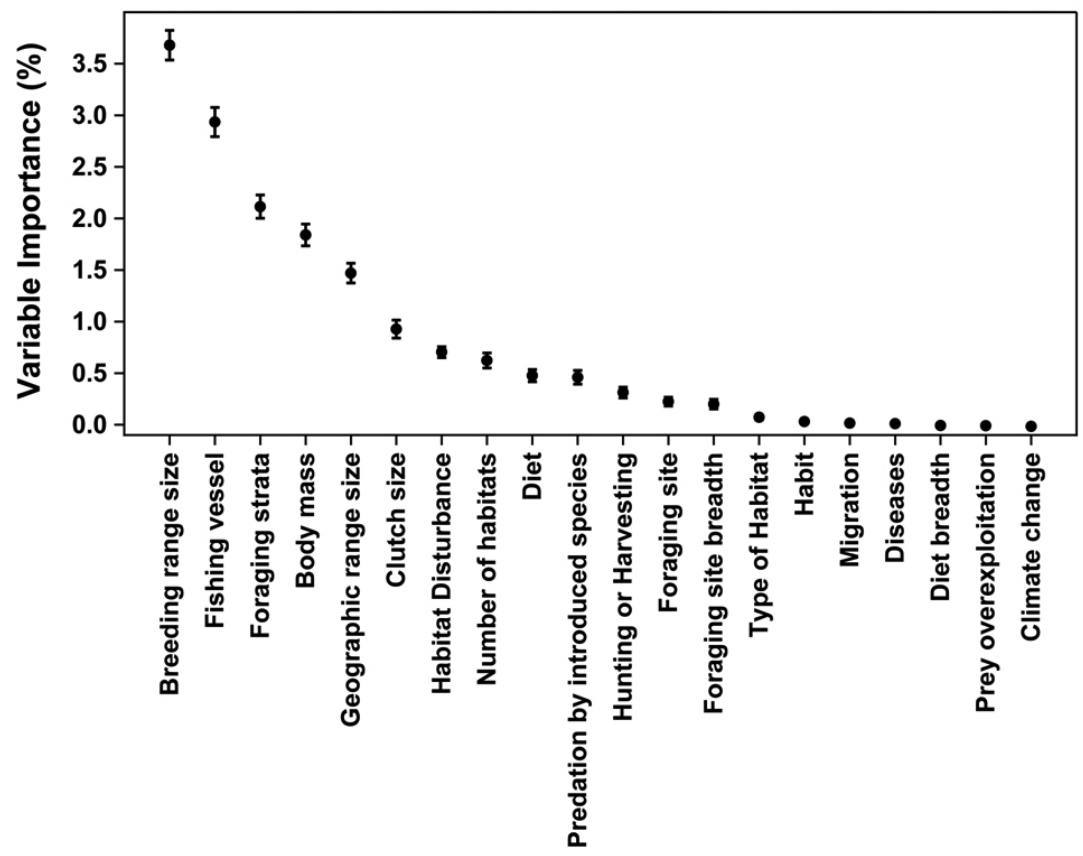

Predictor of Extinction Risk

Figure 2. Relative importance of intrinsic biological features and external threats in predicting seabird extinction risk in Brazil measured by reduction in classification accuracy upon a stepwise removal of each variable in a set of 499 random forest trees. Error bars represent standard deviation.

(Croxall et al. 2012). To make matters even worse, the few areas covered by MPAs in Brazil have small size.

We found that total breeding range size was a pivotal biological feature driving seabird extinction risk even after removing species classified by IUCN (2011) as threatened under criterion B. Seabirds generally have distinct size of breeding range and winter range and most part of Brazilian seabirds does not breed within Brazilian limits (Sick 2001).
Despite wintering range is important mainly during resting period, breeding site should be more sensible to impacts, and when smaller, more chance of offspring be negatively impacted by anthropic actions (Neves et al. 2006).

Clutch size is also figured as an important variable driving extinction risk in our model in accordance with results reported in previous studies (Krüger \& Radford 2008). Species with small clutch sizes and small breeding populations 
A

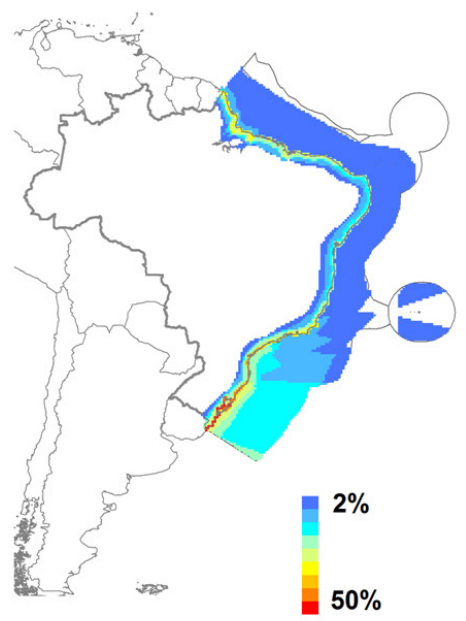

B

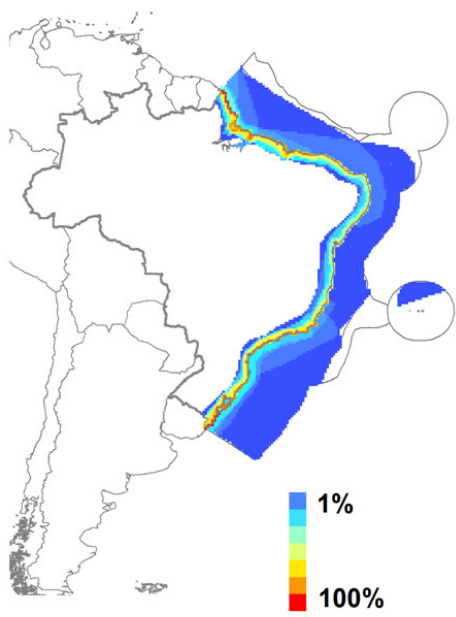

C

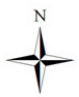

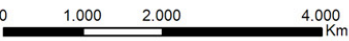

Figure 3. Species richness patterns of seabirds in Economic Exclusive Zone in Brazil (A), of species predicted under high extinction risk (B), and species predicted under low extinction risk (C).

are more vulnerable and have limited capacity to recover after impacts (Croxall et al. 2012). In fact, pelagic seabirds, which have the smaller clutch sizes, are the most threatened group and have faced faster population declines than coastal species (see Croxall et al. 2012).

Only two species currently classified as threatened by the IUCN Red list (IUCN 2011), were predicted as non-threatened by our model (the Trindade Pretel Pterodroma arminjoniana and Olrog's Gull Larus atlanticus). These species are listed as Vulnerable by the IUCN mainly because of their very small breeding range and small populations (IUCN 2011). However, the status of Pterodroma arminjoniana would needs a re-evaluation if the breeding population of Round Island (in the Indian Ocean) was confirmed to be part of this species (Birdlife International 2013).

In 2006, the Internation Commission for the Conservation Atlantic Tunas (ICCAT) request an assessment of threat from their fisheries to seabirds that occur in their jurisdiction (Tuck et al. 2011), and Brazilian government created a national conservation plane for seabirds inhabiting their territory (Neves et al. 2006). We showed that for seabirds, main causes of decline are threat from fishing vessel and habitat disturbance. Longline vessels are reported caughting a large and unsustainnable number of seabirds (Tuck et al. 2011). However, these threats are also geographically structured and species with high and low relative extinction risk occur in very different sites. Even though species richness is higher in the coast; species with higher extinction risk are located in the south, far from the coast. Thus, sites with high richness are not necessarily those more important to seabird conservation.

The Brazilian network of MPAs was designed mainly to cover coastal environments, largely neglecting the open sea biota (Game et al., 2009). Although the establishment of MPAs is of paramount importance, evaluation of their effectiveness must be included within conservation schemes (Magris et al.2013) as well as mapping the geography of extinction risk. Currently, site-selection of MPAs for safeguarding seabirds has been proposed using different approaches (e.g. protection of areas associated with breeding colonies and aggregations of non-breeding birds, and protection of migratory bottlenecks) (Grecian et al. 2012; Thaxter et al. 2012). We believe that including sites that comprise geographic range of species with high extinction risk, as those showed here, could increase spatial prioritization effectiveness avoiding species losses.

Here we show that drivers of extinction risk act in a synergistic way. Further, Brazilian MPAs are not effective to protect seabirds being unable to cover a minimum of $10 \%$ of species' ranges for those species under high extinction risk. Therefore, we suggest that conservation of seabirds in Brazil should be considered high priority given their low current level of protection and that our work help in the discussion on how and when to implement conservation actions in Brazil.

\section{Acknowledgements}

We thank José Alexandre F. Diniz Filho and two anonymous reviewers for comments on an early version of this paper. 
Thanks also to Adriano Melo for helping with R scripts. NM receives a PhD scholarship from CAPES. DB and $\mathrm{RDL}$ receive research productivity grants from $\mathrm{CNPq}$ (\#305631/2009-8 and \#304703/2011-7, respectively). CNPq, CAPES, and Conservation International Brazil have continuously supported research in the Conservation Biogeography Lab.

\section{References}

Bennett PM \& Owens IPF, 1997. Variation in extinction risk among birds: chance or evolutionary predisposition? Proceedings of the Royal Society of London B, 264:401-408. http://dx.doi.org/10.1098/rspb.1997.0057

BirdLife International, 2013. Species factsheet: Pterodroma arminjoniana. Available from: <http://www.birdlife.org $>$.

Breiman L et al., 1984. Classification and regression trees. Florida: Chapman and Hall.

Cardillo $\mathrm{M}$ et al., 2006. Latent extinction risk and the future battlegrounds of mammal conservation. Proceedings of the National Academy of Sciences of the United States of America, 103:4157-61. PMid:16537501 PMCid:1449663. http://dx.doi.org/10.1073/pnas.0510541103

Croxall J et al., 2012. Seabird conservation status, threats and priority actions: a global assessment. Bird Conservation International, 22:1-34. http://dx.doi.org/10.1017/ S0959270912000020

Davidson AD et al., 2009. Multiple ecological pathways to extinction in mammals. Proceedings of the National Academy of Sciences of the United States of America, 106:10702-10705. PMid:19528635 PMCid:2705575. http://dx.doi.org/10.1073/ pnas.0901956106

De'ath G \& Fabricius KE, 2000. Classification and regression trees: a powerful yet simple technique for ecological data analysis. Ecology, 81:3178-3192. http://dx.doi. org/10.1890/0012-9658(2000)081[3178:CARTAP]2.0.CO;2

Game ET et al., 2009. Pelagic protected areas: the missing dimension in ocean conservation. Trends in Ecology \& Evolution, 24:360-369. PMid:19324450. http://dx.doi. org/10.1016/j.tree.2009.01.011

Gamer M et al., 2010. irr: various coefficients of interrater reliability and agreement. version 0.83 . [software]. Available from: <http://CRAN.R-project.org/package=irr $>$.

Gaston KJ \& Blackburn TM, 1995. Birds, body size and the threat of extinction. Philosophical Transactions of the Biological Sciences, 347:205-212. http://dx.doi.org/10.1098/ rstb.1995.0022

Grecian WJ et al., 2012. A novel projection technique to identify important at-sea areas for seabird conservation: an example using Northern gannets breeding in the North East Atlantic. Biological Conservation, 156:43-52. http:// dx.doi.org/10.1016/j.biocon.2011.12.010
Halpern BS et al., 2008. A global map of human impact on marine ecosystems. Science, 319:948-952. PMid:18276889. http://dx.doi.org/10.1126/science.1149345

International Union for the Conservation of Nature - IUCN. IUCN Red List of threatened species. version 2011.2. Available from: <http://www.iucnredlist.org $>$.

Krüger O \& Radford AN, 2008. Doomed to die? Predicting extinction risk in the true hawks Accipitridae. Animal Conservation, 11:83-91. http://dx.doi. org/10.1111/j.1469-1795.2007.00155.x

Liaw A \& Wiener M, 2002. Classification and regression by randomForest. Rnews, 2-3:18-22.

Magris RA et al., 2013. Analysis of progress towards a comprehensive system of marine protected areas in Brazil. Natureza \& Conservação, 11(1):81-97. http://dx.doi. org/10.4322/natcon.2013.013

Neves T et al., 2006. Plano de ação nacional para a conservação de albatrozes e petréis. Brasilia: Ibama.

Pinsky ML et al., 2011. Unexpected patterns of fisheries collapse in the world's oceans. Proceedings of the National Academy of Sciences of the United States of America, 108:8317-22. PMid:21536889 PMCid:3100948. http://dx.doi.org/10.1073/ pnas. 1015313108

Purvis A et al., 2000. Predicting extinction risk in declining species. Proceedings of Royal The Royal Society of London B, 267:1947-52. PMid:11075706. http://dx.doi.org/10.1098/ rspb.2000.1234

Ridgely RS et al., 2011. Digital distribution maps of the birds of the western hemisphere. version 3. Arlington: BirdLife International and NatureServe.

Sergio F et al., 2008. Top Predators as Conservation Tools: Ecological Rationale, Assumptions, and Efficacy. Annual Review of Ecology, Evolution, and Systematics, 39:1-19. http://dx.doi.org/10.1146/annurev.ecolsys.39.110707.173545

Sick H, 2001. Ornitologia Brasileira. Rio de Janeiro: Nova Fronteira.

Sodhi NS \& Ehrlich PR, 2010. Conservation Biology for All. Oxford: Oxford University Press. http://dx.doi.org/10.1093/ acprof:oso/9780199554232.001.0001

Stotz DF et al., 1996. Neotropical birds: Ecology and Conservation. Chicago: University of Chicago Press, v. 3.

Thaxter CB et al., 2012. Seabird foraging ranges as a preliminary tool for identifying candidate Marine Protected Areas. Biological Conservation, 156:53-61. http://dx.doi. org/10.1016/j.biocon.2011.12.009

Toropova C et al., 2010. Global ocean protection: present status and future possibilities. Cambridge: UNEP-WCMC.

Tuck GN et al., 2011. An assessment of seabird-fishery interactions in the Atlantic Ocean. ICES Journal of Marine Science, 68:1628-1637. http://dx.doi.org/10.1093/icesjms/ fsr118 